Nordic Concrete Research - Publ. No. NCR 62 - ISSUE 1 / 2020 - Article 5, pp. 87-106

\begin{tabular}{|c|c|}
\hline$\checkmark$ sciendo & 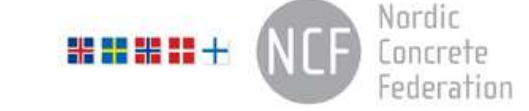 \\
\hline $\begin{array}{l}\text { (C) Article authors. This is an open access article distributed under } \\
\text { the Creative Commons Attribution-NonCommercial-NoDerivs } \\
\text { licens. (http://creaticecommons.org/licenses/by.nc-nd/3.0/). }\end{array}$ & $\begin{array}{l}\text { ISSN online } 2545-2819 \\
\text { ISSN print } \quad 0800-6377\end{array}$ \\
\hline DOI: $10.2478 /$ ncr-2020-0002 & $\begin{array}{r}\text { Received: Feb 19, } 2020 \\
\text { Revision received: June 19, } 2020 \\
\text { Accepted: June 22, } 2020\end{array}$ \\
\hline
\end{tabular}

\title{
Activation Energy for the Concrete Maturity Model - Part 1: Compressive Strength Tests at Different Curing Temperatures
}

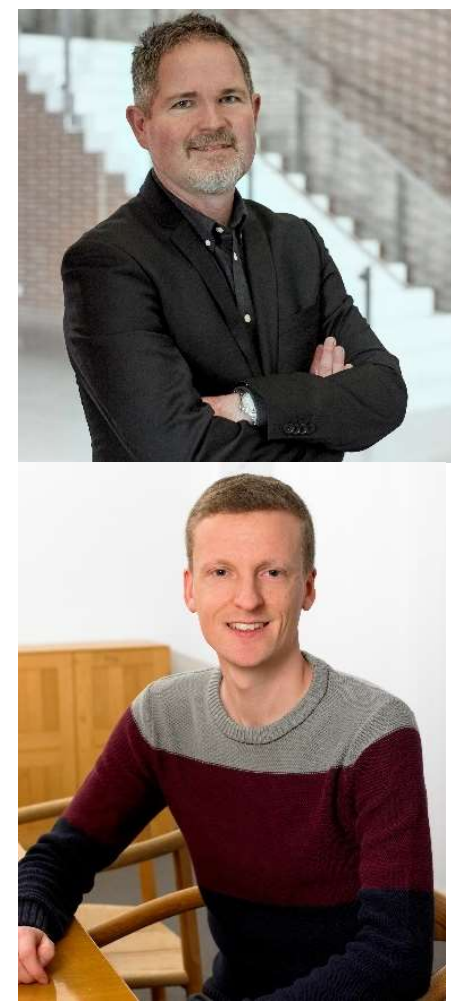

Claus Vestergaard Nielsen, M.Sc., Ph.D.

Concrete Expert, Danish Technological Institute

Gregersensvej, DK-2630 Taastrup

cln@teknologisk.dk

Martin Kaasgaard, M.Sc.

Business Manager, Danish Technological Institute

Gregersensvej, DK-2630 Taastrup

mkaa@teknologisk.dk

\begin{abstract}
The article addresses the modelling of the maturity of concrete. The apparent activation energy is the backbone of the Arrhenius model, which is typically used to model the maturity of concrete. The maturity (or the equivalent age) is influenced by the curing temperature and it is applied when modelling the hydration process and the hardening of concrete for instance in order to forecast the early-age strength to determine the time for removal of formwork or the time for prestressing. Part 1 of the article describes the background for the maturity model and the test series carried out at the DTI concrete lab.
\end{abstract}


Laboratory tests at different curing temperatures (from $5^{\circ} \mathrm{C}$ to $60^{\circ} \mathrm{C}$ ) are presented and the compressive strength results are modelled according to the original Freiesleben Hansen and Pedersen maturity model that has been applied in the field for many years. The tests include five different concretes, using three different cement types and the addition of fly ash. There are significant differences especially when considering the later-age strength modelling at either low temperatures or at high temperature curing.

Key words: Activation energy, maturity, early-age strength, curing.

1.

\section{INTRODUCTION}

This paper contains Part 1 of a two-paper article. Part 1 describes the concrete maturity model and a new test series undertaken at the DTI laboratory with different cement types and binder combinations. Part 2 of the article contains a suggestion for an updated maturity model based on the widely used Freiesleben Hansen and Pedersen (FHP) model. Part 2 also contains discussion of the results and a comparison with other reported tests on the subject.

The importance of the maturity model for concrete is increasing due to higher demands for increased productivity on the building site and in the precast factory. Furthermore, the availability of sophisticated sensors makes it possible to monitor the concrete temperature continuously and predict maturity and strength development in real time. Therefore, the need for updated knowledge of the input parameters for maturity modelling is becoming more pronounced in order to obtain valid predictions and documentation. This is a trend that is expected to increase significantly as the sensor technology becomes more advanced and the equipment becomes cheaper.

\subsection{Background}

In Denmark the so-called Freiesleben Hansen and Pedersen (FHP) model [1], which is based on the Arrhenius concept, is normally used. The FHP model has been applied in Denmark since the early 1980s in pretty much the same formulation and with the same input parameters for all binder types and combinations.

The FHP model, which is described in the next section, is also suggested in a simplified version by Eurocode 2 [2] and in the fib Model Code [3] when the development of concrete properties with age and varying temperatures are to be modelled and considered. Both Eurocode 2 (EC2) and the fib Model Code assume the apparent activation energy, not being a function of temperature. However, this could lead to unconservative model results, where the strength is over-predicted.

The main purpose for the maturity modelling of concrete is to predict the development of hydration and strength as a function of the age of the concrete and the temperature history. The compressive strength of concrete and its development are the most important design parameters for structural concrete and most other design parameters are related to it. Therefore, it is very important to have accurate and valid model tools to assess the strength values during hardening. Modelling of maturity and concrete hardening is typically applied for the following two scenarios: 
- Modelling of the early-age strength development for instance when designing and planning post-tensioning of concrete structures, removal of interim supports and formwork. This is typically of main interest within a time frame of one or two days after casting. Especially for cold conditions during wintertime, the rate of strength gain may govern the construction speed. Furthermore, the knowledge of early-age strength development under cold conditions is needed to determine when the newly cast concrete is resistant against freezing.

- Modelling of early-age thermal cracking due to restrained deformations during the hardening period. For instance, when the inner part of a massive concrete structure heats up followed by a cool-down period, or when different concrete volumes are cast together at different times the non-uniform development of strength and stiffness may cause earlyage thermal cracking. This may take several weeks depending on the ambient conditions and the geometry of the structure.

During the hardening of a cross-section, different temperatures occur at different positions because of heat generation during the hydration process [4]. Normally the zones close to the surfaces are colder than the centre area because of the heat losses to the surroundings. The spatial temperature variation means that the maturity differs across the cross-section. Likewise do the mechanical strength, the E-modulus, creep and shrinkage, etc. Hence, if the activation energy and the maturity development for the concrete are not modelled accurately, the early-age thermal cracking analysis is not going to yield trustworthy results.

Especially in Northern Europe and in Canada where the temperatures during the winter season are relatively low (often close to the freezing point and below) there is an increased need to optimise the construction processes to keep the productivity up. This is the case for both site-cured and precast concrete structures. Therefore, this topic has been investigated in particular at universities in the Nordic countries [7, 8].

\subsection{Scope and research significance}

This article gives a brief description of the maturity model based on the Arrhenius concept. The apparent activation energy is a vital part of this model and different approaches has been suggested for this parameter. The FHP model has been applied extensively around the world since it was proposed more than 40 years ago [1] and it is the basis for both Eurocode 2 and the fib Model Code. However, it is needless to say, that the concrete mixes have changed significantly since then, new binders have emerged, and supplementary cementitious materials (SCM's) have been introduced. Therefore, the main focus of this article has been to investigate the validity of the original FHP model and to suggest a new temperature dependency for the apparent activation energy.

The investigation has been limited to the concrete mix designs, with rather low water to binder ratios, which is often used for civil engineering structures such as bridges and tunnels.

The results give new information on the importance of applying a temperature dependent activation energy when modelling concrete maturity for early-age strengths. Furthermore, the results show some important effects of high temperature curing in terms of reduced later-age strengths. This so-called cross-over effect is found to be very dependent on the binder system. 


\section{2.}

\section{THE MATURITY MODEL}

In the present article only the maturity concept based on the Arrhenius model is applied since it has been the basis for the modelling approaches in Eurocode 2 and in the fib Model Code [2,3]. Other concepts have been suggested in the past and a thorough summary of the various approaches and their history is given by Carino [5]. For a more extensive description of the maturity concept and its association with the degree of hydration the reader is referred to [7] which contains a long list of relevant references on the topic.

In the present article the maturity age is denoted $M$ and the real age is denoted $t$ [1]. They have the same unit (typically hours or days). The maturity age is also often denoted $t_{e}$ (equivalent age) in the literature $[5,7]$.

\section{1}

The FHP model

According to the FHP model [1] the maturity age $(M)$ is equal to the equivalent age as if the development took place at a constant reference temperature (normally taken to be $20^{\circ} \mathrm{C}$ ). At temperatures above the reference temperature, the maturity increases at a faster rate than the real age and for lower temperatures, the maturity develops slower than the real age. The reason for the choice of $T_{\text {ref }}=20^{\circ} \mathrm{C}$ is that the standard tests for concrete mechanical properties typically include a wet curing period at this temperature for 28 days before the test is carried out. Thereby, the standard tests yield maturity age identical to the real age by default.

The ratio between the rate of maturity and the rate of ageing is termed the rate function and it is denoted $H$ :

$$
H(T)=\frac{\mathrm{d} M(T)}{\mathrm{d} t}
$$

where $M=$ maturity age (hours); $T=$ concrete temperature $\left({ }^{\circ} \mathrm{C}\right)$ and $t=$ real age (hours). The relationship between $H$ and $T$ is defined in the maturity model as shown below. One of the important input parameters is the so-called apparent activation energy $E_{a}$ (Figure 1) which is an essential part of the Arrhenius concept.

The FHP model is based on the Arrhenius concept with a reference temperature $T_{\text {ref }}=20^{\circ} \mathrm{C}$ and it reads [1]:

$$
H(T)=\exp \left\{\frac{E_{a}(T)}{R} \cdot\left(\frac{1}{273^{\circ} \mathrm{C}+T_{\mathrm{ref}}}-\frac{1}{273^{\circ} \mathrm{C}+T}\right)\right\}
$$

where $E_{a}=$ the apparent activation energy $(\mathrm{J} / \mathrm{mol})$ ) for concrete, which is found (empirically) to depend on the curing temperature $T$, and $R=8.314 \mathrm{~J} / \mathrm{mol} /{ }^{\circ} \mathrm{C}$ (the universal gas constant). Sometimes the ratio $E_{a} / R$ is used to denote the apparent activation energy, having the unit ${ }^{\circ} \mathrm{C}$. It is clearly seen from (2) that when $T=T_{\text {ref }}=20^{\circ} \mathrm{C}$, the rate function $H$ becomes equal to unity.

In Figure $1 \mathrm{a}$ few examples of the apparent activation energy for concrete are shown, as a function of the temperature, suggested in the literature and in the present article. In the following section these models are explained further. 
One of the models shown in Figure 1 with dashed lines, is the FHP model given below in (3), which was based on a large series of tests [1]. Freiesleben Hansen and Pedersen [1] originally suggested the following bi-linear relationship for the apparent activation energy:

$$
E_{a}(T)=\left\{\begin{array}{c}
33500 \frac{\mathrm{J}}{\mathrm{mol}}, \text { for } T \geq T_{\mathrm{ref}}=20^{\circ} \mathrm{C} \\
33500 \frac{\mathrm{J}}{\mathrm{mol}}+K_{1}\left(20^{\circ} \mathrm{C}-T\right), \text { for } T<T_{\mathrm{ref}}
\end{array}\right.
$$

where the constants $E_{a 20}=33500 \mathrm{~J} / \mathrm{mol}$ and $K_{1}=1470 \mathrm{~J} / \mathrm{mol} /{ }^{\circ} \mathrm{C}$ were fitted to the test results. In order to fit the curing temperatures below $20^{\circ} \mathrm{C}$, a decreasing relationship between $E_{a}$ and temperature $T$ was suggested as shown in Figure 1 (dashed line).

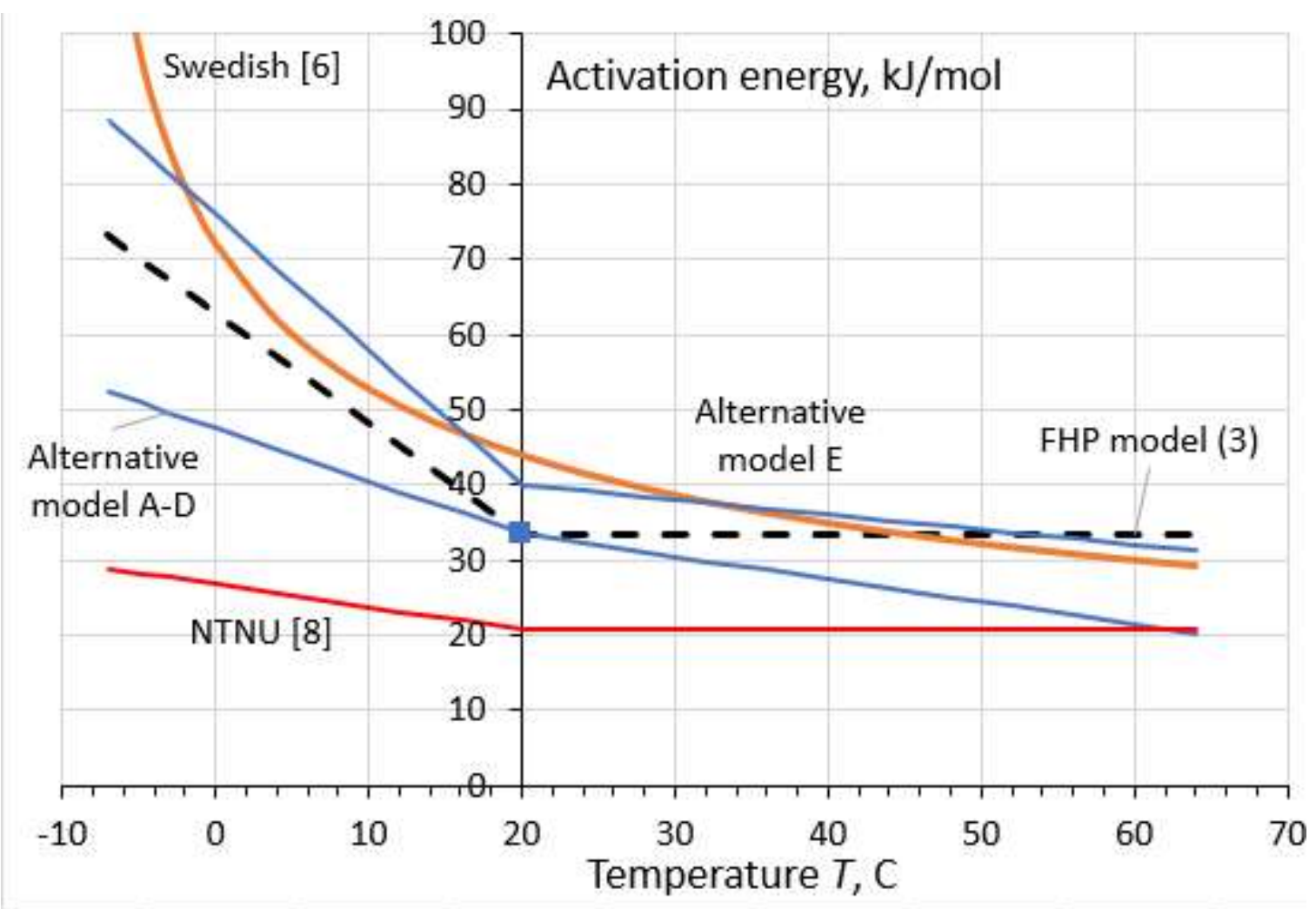

Figure 1 - Apparent activation energy $E_{a}$ based on different models, including the new models suggested in Part 2 of the present article (blue lines). Note that for temperatures below $20^{\circ} \mathrm{C}$ increasing activation energy results in decreasing rate function $H(T)$ and vice versa. This is clearly seen when comparing the red NTNU curve with the corresponding $H$ - $T$ relationships given in Figure 2.

The tests behind the FHP model in (3) consisted of 47 temperature histories on a single concrete mix [1]. The concrete mix design was based on a rapid hardening ordinary Portland cement (OPC) and aggregates sourced from a Danish gravel pit. The exact mix design is not reported in [1] but it is stated that the cement content was $325 \mathrm{~kg} / \mathrm{m}^{3}$ and w/c $=0.52$. The temperature histories varied with time and ranged from $-10^{\circ} \mathrm{C}$ up to $+80^{\circ} \mathrm{C}$, representing various realistic hardening scenarios for different weather conditions and different concrete dimensions. 
The real age of the samples at the time of testing was up to one week and the compressive strengths recorded reached up to approximately $30 \mathrm{MPa}$. Hence, the standardised 28-days strength was not recorded or reported in the investigation. The relationships given in (2) and (3) show an almost perfect fit to the FHP test series up to a maturity age of $M=100$ hours (4 days). Hence, the FHP model was originally developed in order to predict the maturity and strength at early ages in order to determine the strength during construction. It was not meant to be extrapolated to later ages as it is being done regularly nowadays.

See Figure 2 for the rate factor $H$ corresponding to the data in Figure 1.

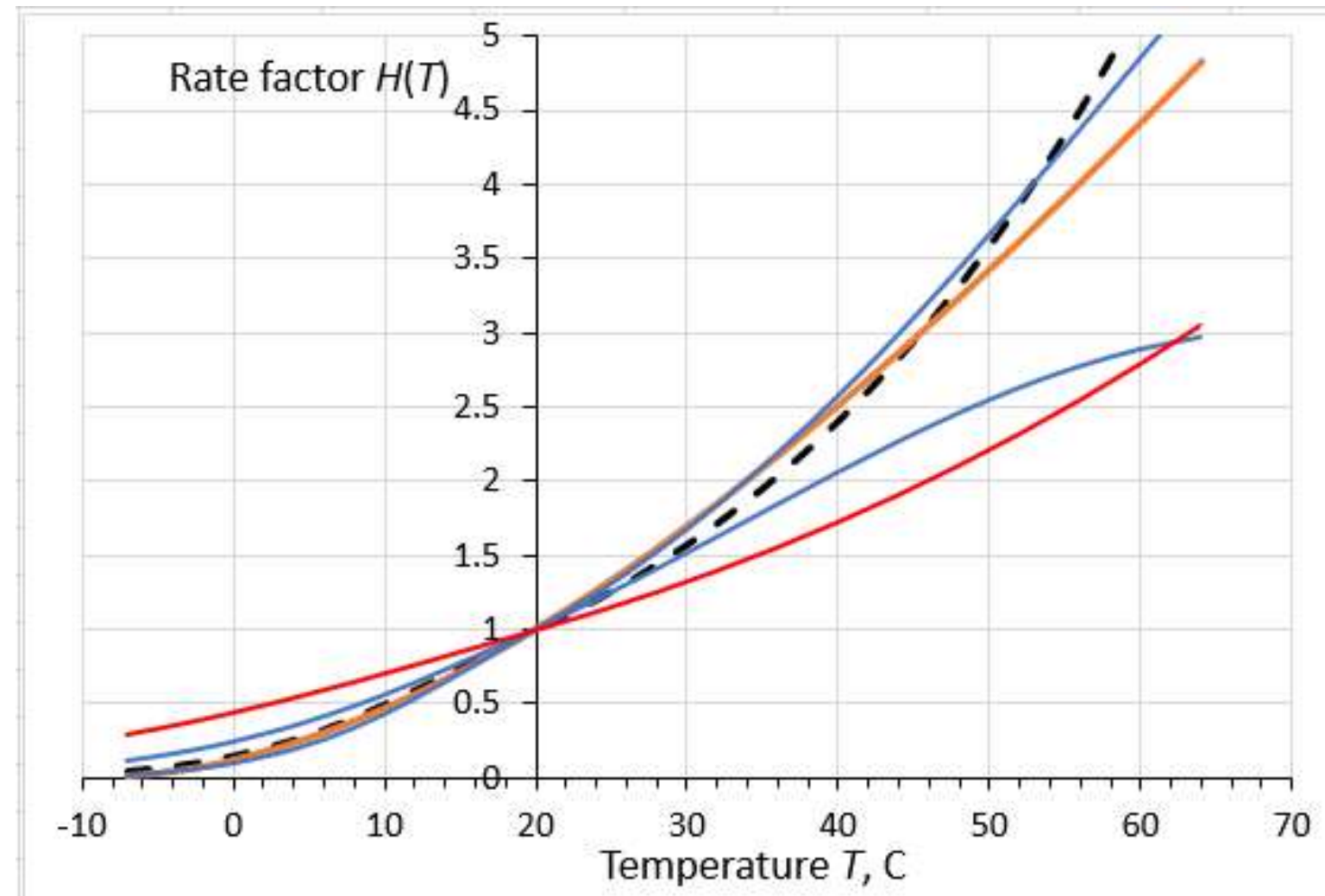

Figure 2 - Rate function H corresponding to the apparent activation energies shown in Figure 1. The curve legends are seen in Figure 1.

\section{$2.2 \quad$ Other maturity models}

In Eurocode 2 [2] the maturity age is calculated by means of (2) where the temperature history is divided into a number of discrete steps $\Delta t_{i}$ in which the temperature can be assumed constantly equal to $T_{i}$. The following summation is carried out over the temperature history, consisting of $N$ time steps:

$$
M=\sum_{i=1}^{N} H\left(T_{i}\right) \cdot \Delta t_{i}
$$

The Eurocode 2 applies a constant value of the apparent activation energy $E_{a}$ equal to $33256 \mathrm{~J} / \mathrm{mol}$ without any temperature dependency [2]. The fib Model Code 2010 [3] applies the same maturity model as Eurocode 2. In both these codes the maturity is named the temperature adjusted age. Hence, neither Eurocode 2 nor the fib Model Code has introduced the temperature variation on $E_{a}$ 
for temperatures below $T_{\text {ref. }}$ As shown in Part 2 of this article, this means that the early-age strength development is over-predicted by the Eurocode 2 and fib Model Code for temperatures near the freezing point (say below $10^{\circ} \mathrm{C}$ ).

In Sweden the Arrhenius model (2) is also applied and it is normally combined with the following temperature dependent function $[6,7]$ :

$$
\frac{E_{a}(T)}{R}=\theta_{\mathrm{ref}}\left(\frac{30^{\circ} \mathrm{C}}{T+10^{\circ} \mathrm{C}}\right)^{\kappa}, T>-10^{\circ} \mathrm{C}
$$

where $\theta_{\text {ref }}=$ apparent activation energy divided with the gas constant at $T_{\text {ref }}=20^{\circ} \mathrm{C}$ and $\kappa=$ a fitting parameter (dimensionless). In [6] the following values were proposed: $\theta_{\text {ref }}=5300{ }^{\circ} \mathrm{C}$ and $\kappa=0.45$, corresponding to $E_{a, 20} \approx 44000 \mathrm{~J} / \mathrm{mol}$ (orange line in Figure 1). In [7] no temperature dependency is found $(\kappa=0)$ and $E_{a}$ is suggested to be approximately $23000 \mathrm{~J} / \mathrm{mol}$, based on compressive strength results obtained from different concretes and two different Swedish cement types (CEM II/A-LL 42.5 and CEM I $42.5 \mathrm{~N}$ SR-3). This is seen to correspond approximately with the red line in Figure 1.

Norwegian investigations at NTNU [8] have been published, using the FHP model in (2) and (3). All the concrete mix designs in the Norwegian investigation had water to binder ratios around 0.40 , meant for bridge structures, and having compressive cylinder strengths at 28 days of approximately 50 to $60 \mathrm{MPa}$. They found that increasing amounts of silica fume (up to $15 \%$ of binder weight) increased the apparent activation energy significantly (from around $21000 \mathrm{~J} / \mathrm{mol}$ for pure CEM I 52.5) up to around $43000 \mathrm{~J} / \mathrm{mol}$ when $15 \%$ silica fume was added. The former is shown with the red line in Figure 1. Two other Norwegian cements were reported in [8], viz. CEM I 42.5 $\mathrm{R}$ and CEM II/A-V 42.5 R, yielding very low activation energies around $7500 \mathrm{~J} / \mathrm{mol}$ and 13300 $\mathrm{J} / \mathrm{mol}$, respectively.

Schindler [9] gives a thorough overview of the different activation energies found in the concrete literature and proposed an analytical model to predict the apparent activation energy based on the composition of the binder. The model was based on the Arrhenius concept in (2) together with the three-parameter exponential model shown in (6). Schindler concluded that $E_{a}$ may be estimated on basis on the chemical composition and the Blaine of the cement. However, no temperature relationship was included. The model was fitted to a large amount of paste tests on United States cements, see [9] for details. Schindler also included the effect of supplementary cementitious materials (SCM's) in terms of fly ash and ground granulated blast furnace slag based on observations found in the literature. Generally, it seems that the analytical model in [9] provides significantly larger values of the apparent activation energies than suggested in (3), being in the range from 40000 to $50000 \mathrm{~J} / \mathrm{mol}$. In general, the Schindler model predicts that the activation energy increases with increased $\mathrm{C}_{3} \mathrm{~A}$ and $\mathrm{C}_{4} \mathrm{AF}$ content and with increased Blaine value of the cement. Furthermore, the activation energy increases with the share of ground granulated blast furnace slag, but it decreases with increased share of fly ash.

\subsection{Strength development model}

Freiesleben Hansen and Pedersen [1] also suggested an exponential model for the development of strength as a function of the maturity age: 


$$
f_{c}(M)=f_{c \infty} \cdot \exp \left\{-\left(\frac{\tau}{M}\right)^{\alpha}\right\}
$$

where $f_{c}=$ compressive strength (MPa); $f_{c \infty}=$ asymptotic value of the compressive strength (MPa) when $M$ approaches infinity (theoretical final strength); $\alpha=$ fitting parameter (-) and $\tau=$ time parameter (hours). This model is often termed the three-parameter-model in the literature [9] because it is fully described via $f_{c^{\infty}}, \alpha$ and $\tau$. The three-parameter model is also used to describe the development of other mechanical properties such as the E-modulus and the tensile strength $[4,10]$ which are closely related to the compressive strength.

Most often values of $f_{c}$ are recorded at $T_{\text {ref }}$ at the following ages: $M=1,3,7,14,28$ and 56 days. Afterwards the strength recordings are used to fit the parameters in (6).

The same model has also proved to be advantageous when modelling the heat development from the hydration process and for definition of the degree of hydration [4].

Eurocode 2 and fib Model Code 2010 [2,3] apply a simpler model, containing only two parameters $\left(f_{c 28}\right.$ and $\left.s\right)$ to be fitted to the recorded strength data:

$$
f_{c}(M)=f_{c 28} \cdot \exp \left\{s\left(1-\left(\frac{28 \text { days }}{M}\right)^{1 / 2}\right)\right\}
$$

where $f_{c 28}=$ strength value at $M=28$ days and $s=$ fitting parameter (-), which is given in Eurocode 2 , depending on the cement strength classes [2]:

- Slow rate cements: $s=0.38($ CEM $32.5 \mathrm{~N})$

- Normal rate cements: $s=0.25($ CEM 32.5 R and $42.5 \mathrm{~N})$

- Rapid rate cements: $s=0.20$ (CEM 42.5 R, 52.5 N and 52.5 R)

Figure 3 shows examples of the models in (6) and (7). The parameters $\tau$ and $\alpha$ in (6) determines the early-age strength rate and the location of the curve along the horizontal axis. Both the threeparameter model in (6) and the EC2 model in (7) yield an S-shaped curve when depicted in a semi-logarithmic diagram.

However, it is generally the authors' experience that (6) provides a better fit than (7), especially when supplementary cementitious materials (SCM) are used [10] and therefore, the three-parameter-model is applied in the present investigation. Moreover, the EC2 model in (7) does not provide any guidance on how to deal with other cement types than CEM I or how to incorporate additions of SCMs. Therefore, it is not recommended to apply the EC2 model without verification by means of test results conducted at different ages. This is further illustrated in the following section by means of the compressive strength results. 
Nordic Concrete Research - Publ. No. NCR 62 - ISSUE 1 / 2020 - Article 5, pp. 87-106

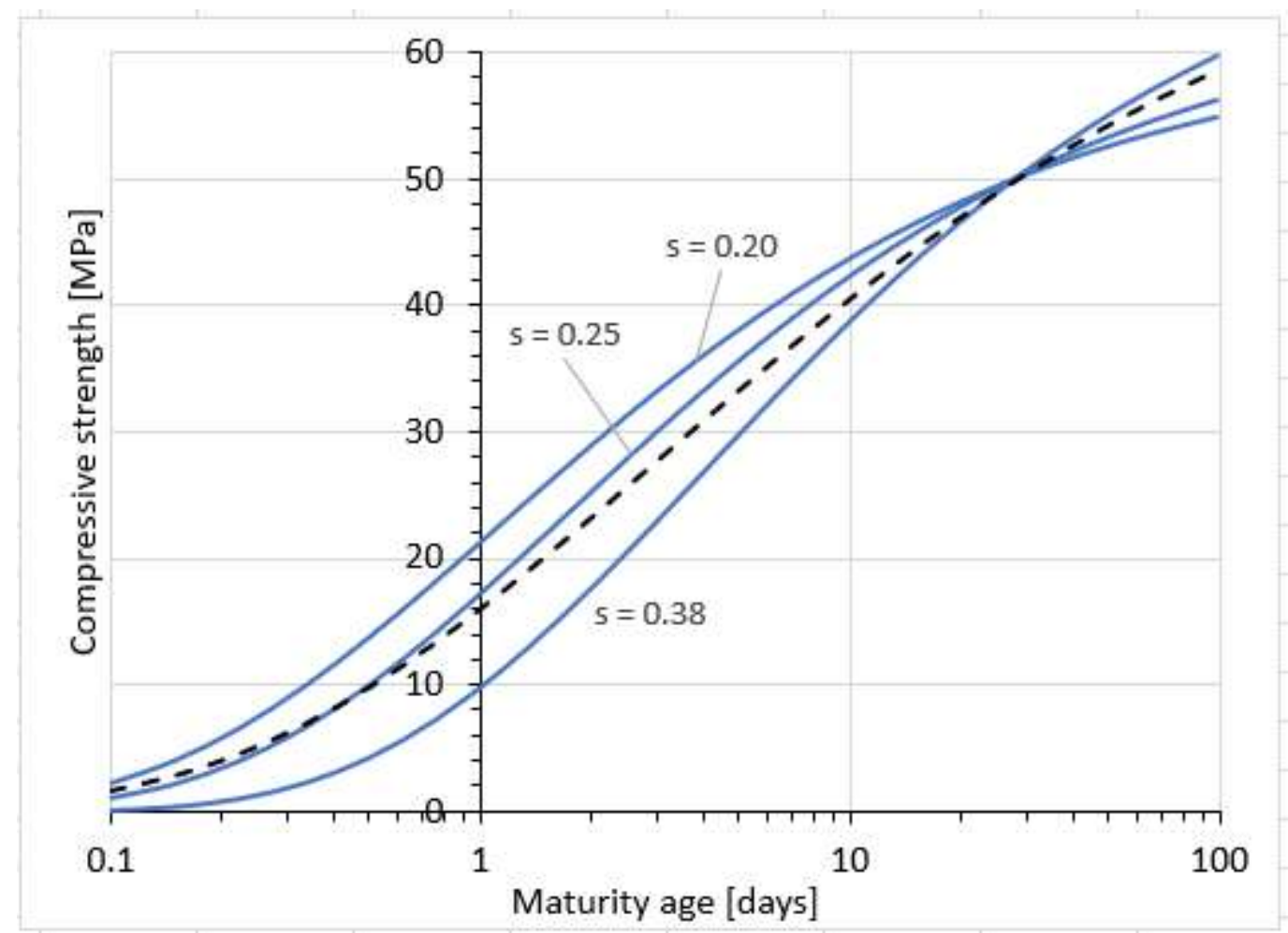

Figure 3 -Compressive strength modelling according to (6) and (7), shown for 28 days strength value of $f_{c 28}=50 \mathrm{MPa}$. The three-parameter model in (6) is shown with dashed line for $\alpha=$ $0.4, \tau=3$ days and $f_{c \infty}=75 \mathrm{MPa}$. The EC2 model in (7) is shown with solid lines for the different $s$-values as indicated.

In 2011 a large test programme was executed at the DTI laboratory [11]. Five concrete types, covering two types of cement, normally used in the Danish concrete industry, were tested at different iso-thermal curing temperatures. Furthermore, a concrete with slag cement was tested. The first series of tests was started in October 2011. However, in the middle of 2012 a second series of tests was carried out to investigate further the very long-term effects for curing temperatures above $20^{\circ} \mathrm{C}$. Finally, a third test series was initiated in 2015 , where four of the five concretes were tested again [12] especially with focus on the early-age strength development and the application of the Danish test standard TI-B 103 [13] for determination of the apparent activation energy.

The concrete mix designs were designated mix A, B, C, D and E. The constituent materials, and the test procedure are described in detail in $[11,12]$ and will not be repeated here. Table 1 summarises the most important information of the concretes and the binder combinations used. The substitution of cement with fly ash corresponds to the limit given in the Danish implementation standard for EN 206. Normally the amounts of fly ash used in Danish ready-mixed concrete is between 15 and $20 \%$ of the binder content. Fly ash was included in the calculation of the w/c ratio with an activity factor of 0.5 . The water to binder ratios are given in Table 1 . 
Nordic Concrete Research - Publ. No. NCR 62 - ISSUE 1 / 2020 - Article 5, pp. 87-106

Table 1 -Concrete mix designs used for the tests. All concretes were air entrained and had target $w / c=0.40$. Aggregates were crushed granite with $D_{\max }=22 \mathrm{~mm}$. See $[11,12]$ for details.

\begin{tabular}{cccccc}
\hline Mix & \multicolumn{2}{c}{ Binder type } & $\begin{array}{c}\text { Binder } \\
\text { content } \\
\left(\mathrm{kg} / \mathrm{m}^{3}\right)\end{array}$ & w/b & $\begin{array}{c}28 \text {-days } \\
\text { strength } \\
(\mathrm{MPa})\end{array}$ \\
\hline ID & Cement type & Composition & 365 & 0.40 & $\begin{array}{c}58.5 \\
59.0^{*}\end{array}$ \\
\hline B & CEM I 42.5 N SR5 & $75 \%$ CEM I + 25\% FA & 400 & 0.35 & $\begin{array}{c}48.4 \\
54.0^{*}\end{array}$ \\
\hline C & CEM I 52.5 N & $100 \%$ CEM I & 365 & 0.40 & 64.1 \\
\hline D & CEM I 52.5 N & $75 \%$ CEM I + 25\% FA & 400 & 0.35 & $\begin{array}{c}68.5 \\
60.0^{*}\end{array}$ \\
\hline E & CEM III/B 42.5 N & $100 \%$ CEM III/B & 360 & 0.40 & $\begin{array}{c}66.1 \\
59.0^{*}\end{array}$ \\
\hline
\end{tabular}

Notes: CEM I 42.5 N SR5, Lavalkali Sulfatbestandig cement and CEM I 52.5 N, Rapid cement, are both from Aalborg Portland A/S. Slag cement CEM III/B 42.5 is produced by CEMEX in Germany. Fly ash was supplied by Emineral. * denotes reference strength results recorded in the third series of tests [12].

For each concrete, compressive strength tests were conducted at the reference temperature $20^{\circ} \mathrm{C}$. Table 1 contains the reference strength after 28 days. Furthermore, four different temperature levels $\left(10,30,45\right.$ and $\left.60^{\circ} \mathrm{C}\right)$ were used in the first and second test series [11]. In the third series only mix A, B, D and $\mathrm{E}$ were tested and five different curing temperature levels were employed $\left(5,10,3045\right.$ and $\left.60^{\circ} \mathrm{C}\right)[12]$ besides the reference temperature.

Curing took place in temperature-controlled water baths and the duration of the iso-thermal curing was varied from less than a day up to half a year (Annex B). The long-term curing was applied in order to obtain information on the temperature effects on the later-age strengths.

For the third series of tests [12], a supplementary curing regime was added for the two highest temperatures $\left(45\right.$ and $60^{\circ} \mathrm{C}$ ) in order to represent realistic curing histories more precisely. Instead of placing the samples in the hot water bath immediately after casting, they were heated slowly to the target temperature inside a climate-controlled chamber until the age of approximately one day. Then the samples were demoulded and placed in the water tank at constant curing temperature until the strength test was carried out.

The results of these supplementary tests are treated further in Part 2 of this article. This slow heating ramp was applied in order to represent the conditions inside a massive structure where the heat of hydration causes high temperatures to build up during the first couple of days after casting.

Mix A and B represent the concrete types normally used for civil engineering structures (bridges and tunnels), where sulfate resistant cement is required. Mix C and D are concretes for buildings and structures exposed to outdoor environment, freeze-thaw action and chlorides. Mix E is normally not used in Denmark as slag cement is not allowed according to the current Danish requirements. 


\section{Reference strengths at $20^{\circ} \mathrm{C}$}

The strength results are shown in Annex A and B for each concrete and for each combination of the iso-thermal curing temperature and age. Table 1 contains the recorded 28-days reference strength results for information. Table 2 contains the model parameters according to (6) fitted to each concrete tested at the reference temperature $\left(20^{\circ} \mathrm{C}\right)$. For each combination of temperature and curing time two or three cylindrical samples were tested. Annex A contains the individual compressive strength results as a function of the age at testing together with the model fitted to the reference test results at $20^{\circ} \mathrm{C}$. For all mixes except mix B, the same model is found to fit the results from all the three different test series. However, for mix B the differences observed in the strength development made it necessary to apply two versions of the three-parameter model.

Table 2 - Three-parameter model parameters fitted to the strength results shown in Annex $A$ and Annex $B$ for $20^{\circ} \mathrm{C}$.

\begin{tabular}{cccc}
\hline $\begin{array}{c}\text { Mix } \\
\text { ID }\end{array}$ & $f_{c \infty}(\mathrm{MPa})$ & $\begin{array}{c}\text { Parameters in (6) } \\
\tau \text { (days) }\end{array}$ & $\alpha(-)$ \\
\hline $\mathrm{A}$ & 96 & 4.9 & 0.42 \\
\hline \multirow{2}{*}{$\mathrm{B}$} & 106 & 12.0 & 0.34 \\
& $123^{*}$ & $14.3^{*}$ & $0.28^{*}$ \\
\hline $\mathrm{C}$ & 75 & 0.93 & 0.55 \\
\hline $\mathrm{D}$ & 98 & 2.4 & 0.42 \\
\hline $\mathrm{E}$ & 76 & 3.1 & 0.88 \\
\hline
\end{tabular}

Note: $*$ denotes parameters obtained for the strength results in the third test series [12].

In the diagrams in Annex A it is seen that the three-parameter-model in (6) provides a good fit to the measured strength data all the way up to about half a year of age. For mixes A and B, the strength increase beyond 28 days is significant, reaching about $20 \mathrm{MPa}$ up to half a year of age. It is not possible to conclude from the test period whether the final strength level has been reached for mixes $\mathrm{A}$ and $\mathrm{B}$.

For mix $\mathrm{C}$ the strength increase beyond 28 days is only found to be about $10 \mathrm{MPa}$ and it seems that the final strength level is reached. However, when fly ash is added (mix D) the strength increase becomes similar to what was observed for mixes A and B. For mix E the strength increase between 28 days and half a year is about $10 \mathrm{MPa}$.

In Figure 4, the $20^{\circ} \mathrm{C}$ strength results are depicted together with the EC2 model given in (7), fitted so that it yields the right 28-days strength. For mixes A and B (Figure 4, top), the EC2 model would suggest $s=0.25$ because of the strength class of the cement. However, it is clearly seen that this overpredicts the early-age strength significantly and $s=0.38$ would be more suitable. 
Nordic Concrete Research - Publ. No. NCR 62 - ISSUE 1 / 2020 - Article 5, pp. 87-106

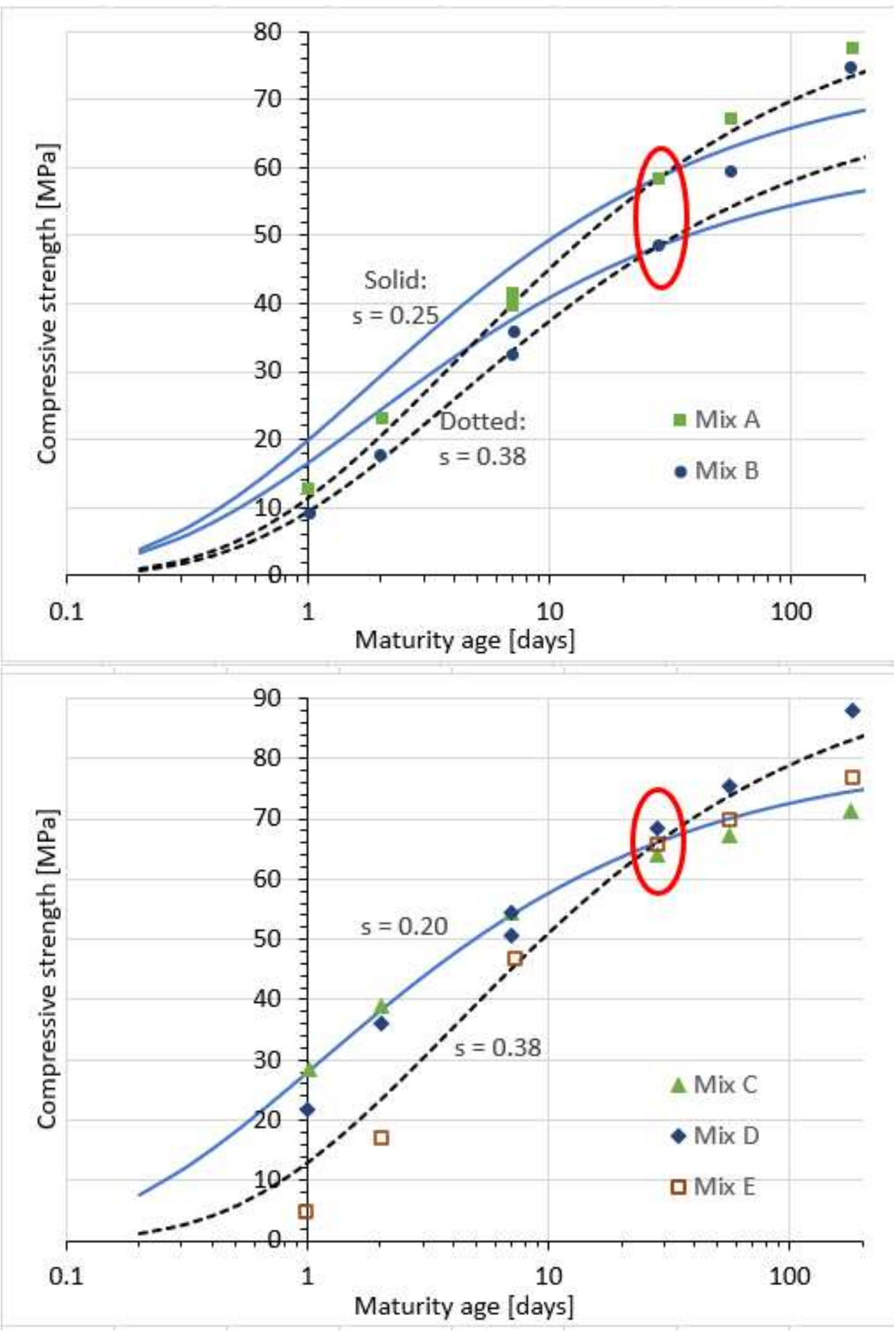

Figure 4 - Compressive strength results at $20^{\circ} \mathrm{C}$ for mixes $A$ to E. The EC2 model in (7) is shown for different s-values as indicated. The red circles indicate the 28-days strength. 
For mixes $\mathrm{C}$ and $\mathrm{D}$ (Figure 4, bottom) a stronger and more rapid hardening cement is used and therefore, $s=0.20$ is suggested in EC2. This is seen to be in good agreement with the strength data for mix C (100\% CEM I 52.5). For mix D it is less precise for early-age strengths and also for the later-age strength development beyond 28 days. For mix E, the delayed strength development at early-age means that the EC2 model with $s=0.38$ overpredicts both the early-age strengths and the later-age strengths significantly.

Hence, the use of the EC2 model in (7) should be considered carefully in relation to the application and the needed accuracy and preferably verified by means of test results on the actual concrete mix design. The EC2 model is only plausible for rough estimates when no detailed data exist.

\section{Strength results at high temperature curing}

From Annex A it is seen that the strength results for curing temperatures below $20^{\circ} \mathrm{C}$ lie to the right of the reference model line and the higher curing temperature results lie (mainly) to the left of this line which is a direct consequence of the maturity model presented earlier. However, for the highest curing temperatures $\left(45\right.$ and $\left.60^{\circ} \mathrm{C}\right)$ there is a clear tendency of the results crossing over the model line at some point. This is the so-called cross-over effect which is described in many investigations on the subject $[7,8,9,14]$.

The cross-over effect is related to the fact that at high early-age curing temperatures, the increased rate of hydration impairs the long-term strengths. In [7] it is stated that the high temperature curing was found to produce a coarser (less uniform) pore structure of the hydration products compared with lower curing temperatures. This is partly in agreement with the findings in [11] where the resistance against chloride ingress was significantly reduced for concretes based on pure CEM I (mixes A and C) whereas the opposite was found for mixes B and D when fly ash was added to the mixes. Here, the causes to this effect are not investigated further.

Kjellsen and Detwiler [14] provided a similar explanation as in [7] based on a large number of mortar tests. They suggested a model where a constant initial apparent activation energy was applied for strength levels up to $20 \%$ of the 28-days reference strength [14]. For strengths above this level, the apparent activation energy was reduced strongly depending on the relative strength. Hence, $E_{a}$ and thereby, the rate function $H$ is a function of both concrete temperature and strength:

$$
H=f\left\{E_{a}\left(T, f_{c}(M)\right), T\right\}
$$

However, this is quite complicated to implement in a practical way because the strength depends on the maturity age which again depends on the strength. This is a topic that seems to be in need of further research.

In the Swedish investigation reported in [7] the hydration process is modelled in three stages and the final stage includes a strength reduction factor depending on the curing temperature. From their test results, strength reductions ranging from 41 to $48 \%$ of the 28 -days reference strength were found. These strength reductions were obtained at $50^{\circ} \mathrm{C}$ curing conditions. Comparing with the results depicted in Annex A, it is seen that the strength reductions of the later-age strengths found in the present investigation at $60^{\circ} \mathrm{C}$ curing temperature are smaller than what was found in the Swedish investigation. They seem to be of the order of magnitude up to $20 \%$ of the 28 -days reference strength. 
Schindler [9] also described the cross-over effect on the later-age strength reduction caused by high temperature curing. He concluded, based on the same test results reported in [14], that the cross-over effect is only related to the mechanical properties as the final degree of hydration does not alter with increased curing temperatures.

For all the concrete types tested here, it is seen from the curves in Annex A that, when the highest curing temperature $\left(60^{\circ} \mathrm{C}\right)$ is applied, the long-term strength level is reduced compared with the lower curing temperatures. For mixes $\mathrm{C}$ and $\mathrm{D}$, it is very pronounced how the long-term strength at $60^{\circ} \mathrm{C}$ is significantly below the reference 28 -days strength level. At $45^{\circ} \mathrm{C}$ curing temperature it is less pronounced but there is still a visible effect on the long-term (final) strength. For mixes A and $\mathrm{B}$, the long-term strength reduction is not as significant as for the other mixes and furthermore, the use of fly ash seems to mitigate the effect somehow.

For mix E with the slag cement, it is seen that the reduction of the later-age strength starts already at curing temperatures from $30^{\circ} \mathrm{C}$. Furthermore, the cross-over effect seems to be significantly higher than for the other concretes tested here. This is further investigated in Part 2 of this article.

4.

\section{CONCLUSIONS}

This is Part 1 of a two-part article. In Part 2, the apparent activation energy $E_{a}$ and the rate function $H(T)$ of the different tested concrete types are analysed further and compared with the FHP model. Furthermore, an alternative version of the FHP model is suggested in Part 2 based on the strength results reported herein. Both Part 1 and Part 2 are published in the current issue of Nordic Concrete Research.

The conclusions regarding the compressive strength results reported in Part 1 are the following:

1. The three-parameter model in (6) is found to give a good fit to the experimental compressive strength results. This is the case for all the five concrete mix designs tested herein.

2. Compared with the simpler model in (7) given in Eurocode 2, the three-parameter model provides a more accurate model, covering the whole time range from very early-age to several months of age. Furthermore, the Eurocode 2 model does not provide any guidance as how to include supplementary cementitious materials into the concrete compositions.

3. For later-age strengths a significant strength reduction is observed for curing temperatures above $45^{\circ} \mathrm{C}$. Therefore, the use of the maturity model to determine later-age strength predictions, is connected with substantial inaccuracy in general at higher curing temperatures.

4. The later-age strength reduction is most severe for the concretes without fly ash addition. The slag cement concrete (CEM III/B $42.5 \mathrm{~N}$ ) also shows substantial later-age strength reductions compared with the reference strength.

\section{REFERENCES}

1. Freiesleben Hansen P \& Pedersen E J: "Måleinstrument til control af betons hærdning" "Maturity Computer for Controlled Curing and Hardening of Concrete"). Nordisk Betong, No. 1, 1977, pp. 21-25. (In Danish).

2. CEN: "Eurocode 2 Design of concrete structures, Part 1-1", EN 1992-1-1, 2004.

3. Federation International du Beton: "Model Code 2010". Fib Bulletin No. 65, Lausanne, Switzerland, 2012, $311 \mathrm{pp}$. 
Nordic Concrete Research - Publ. No. NCR 62 - ISSUE 1 / 2020 - Article 5, pp. 87-106

4. Nielsen C V: "Modeling the heat development of concrete associated with cement hydration”. Special Publication ACI SP-241, Concrete heat development: Monitoring, prediction and management, American Concrete Institute, Farmington Hills, MI, USA, 2007, pp. 95 109.

5. Carino N J: "The maturity method: Theory and Applications". Cement, Concrete and Aggregates, CCAGDP, Vol. 6, No. 2, 1984, pp. 61-73.

6. Jonasson J E, Groth P \& Hedlund H: "Modelling of temperature and moisture field in concrete to study early age movements as a basis for stress analysis". Proceedings, International RILEM Symp.: Thermal Cracking in Concrete at Early Ages, RILEM Proceedings 25, E\&FN Spon, pp. 45-52.

7. Fjellström P, Jonasson J E, Emborg M \& Hedlund H: "Model for concrete strength development including strength reduction at elevated temperatures". Nordic Concrete Research, No. 45, 2012, pp. 25-44.

8. Kanstad T, Hammer T A, Bjøntegaard Ø \& Sellevold E J: "Mechanical properties of young concrete: Part I Experimental results related to test methods and temperature effects". $M a-$ terials and Structures, Vol. 36, 2003, pp. 218-225.

9. Schindler A K: "Effect of temperature on hydration of cementitious materials". ACI Materials Journal, Vol. 101, No. 1, 2004, pp. 72-81.

10. Nielsen C V: "Early-age requirements for concrete for civil structures". Proceedings, fib Congress: Improving Performance of Concrete Structures, Mumbai, India, 2014.

11. Kaasgaard M \& Pade C: "Influence of curing temperature and maturity on chloride permeability of concrete containing fly ash or slag". Nordic Concrete Research, No. 48, 2013, pp. $1-11$.

12. Aarre T \& Kaasgaard M: "Influence of curing temperature on strength development of concrete". Key Engineering Materials, Vol. 711, 2016, 118-125.

13. TI-B 103, "Prøvningsmetode Aktiveringsenergi i den relative hastighedsfunktion" ("Test method for activation energy for concrete"). Danish Technological Institute, Taastrup, Denmark, 1994. (In Danish).

14. Kjellsen K O \& Detwiler R J: "Later-age strength prediction by a modified maturity method". ACI Materials Journal, Vol. 90, No. 3, 1993, pp. 220-227. 


\section{ANNEX A: COMPRESSIVE STRENGTH DEVELOPMENT}

Compressive strength results depicted as a function of real age. Tested in accordance with EN 12390-3. Note semi-logarithmic time-axis. The red circles indicate the 28-days reference strengths measured at $20^{\circ} \mathrm{C}$. The solid line depicts the model based on (6) and the parameters in Table 2. The results correspond to the test results given in Annex B.

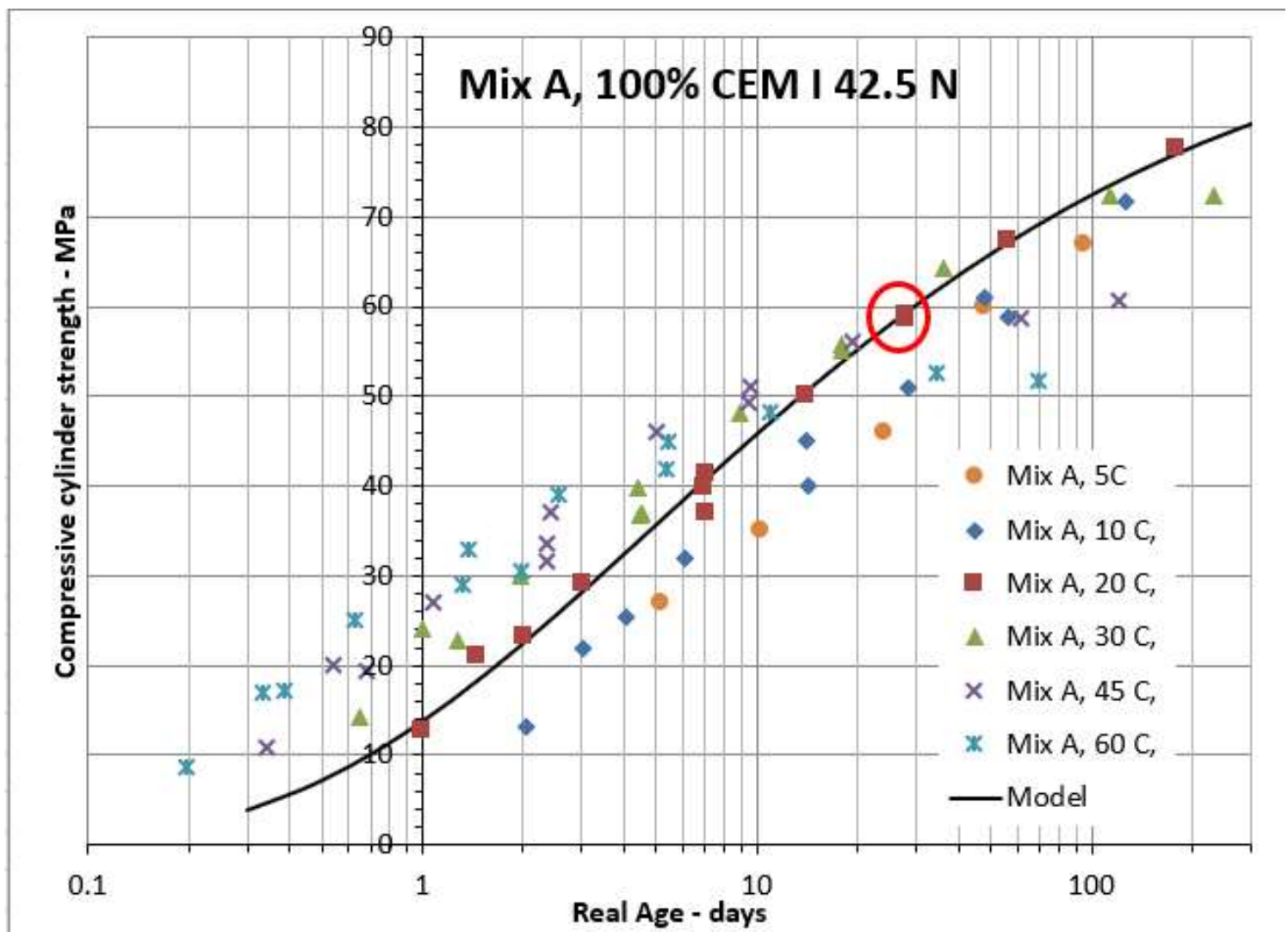


Nordic Concrete Research - Publ. No. NCR 62 - ISSUE 1 / 2020 - Article 5, pp. 87-106
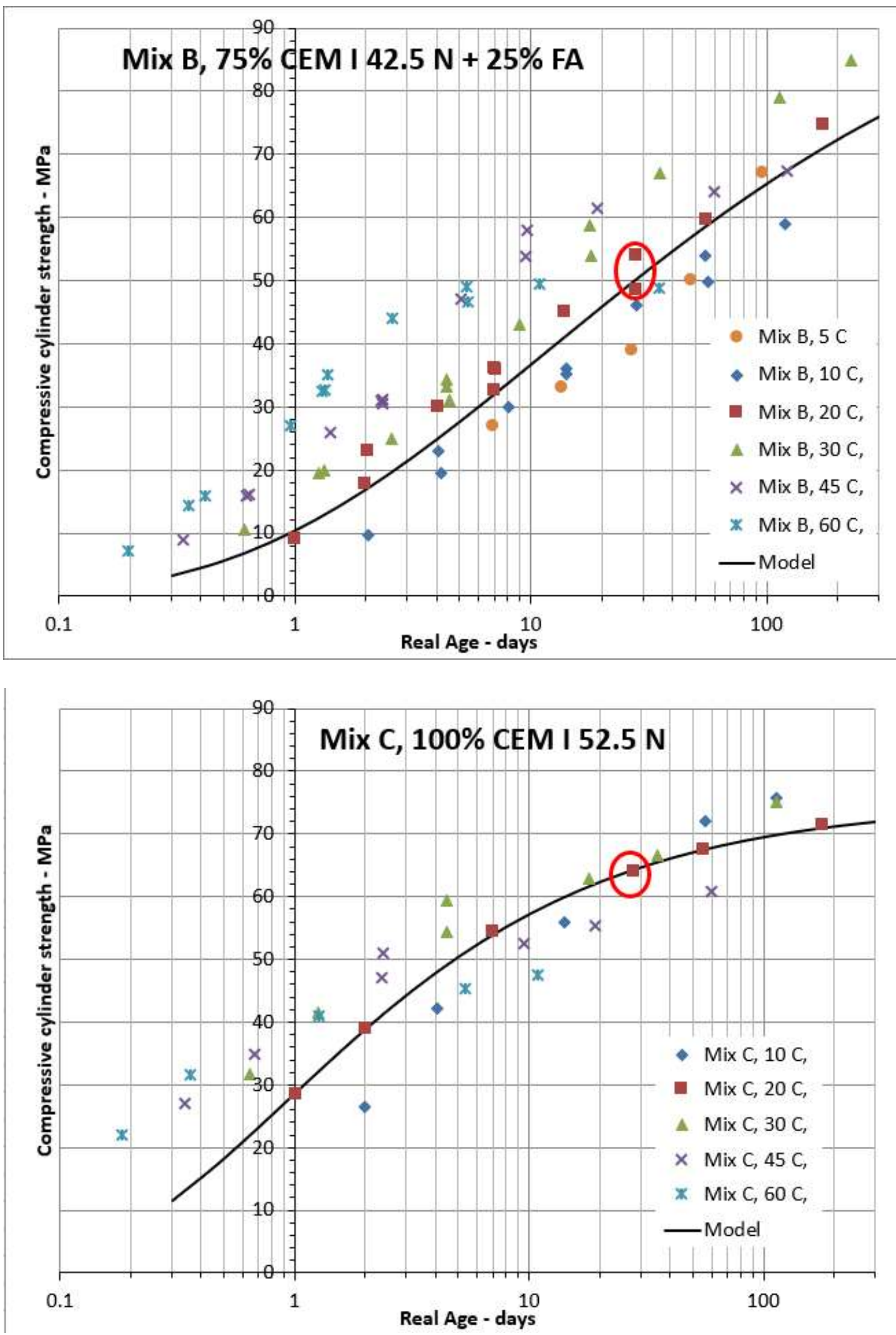
Nordic Concrete Research - Publ. No. NCR 62 - ISSUE 1 / 2020 - Article 5, pp. 87-106
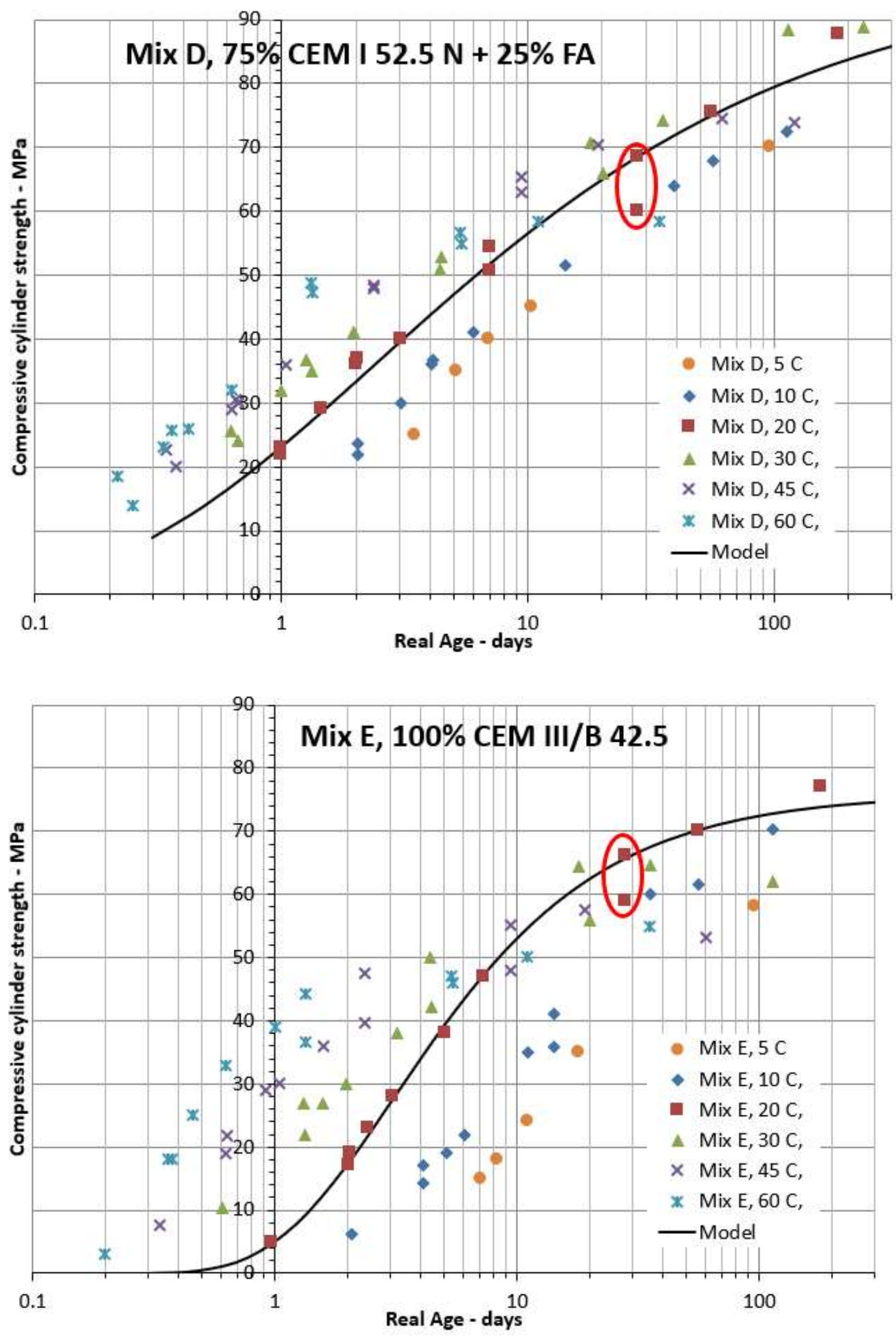
Nordic Concrete Research - Publ. No. NCR 62 - ISSUE 1 / 2020 - Article 5, pp. 87-106

ANNEX B: COMPRESSIVE STRENGTH RESULTS OBTAINED AT DIFFERENT ISOTHERMAL CURING TEMPERATURES

\begin{tabular}{|c|c|c|c|c|c|}
\hline \multirow[b]{2}{*}{$\begin{array}{l}\text { Nominal } \\
\text { temp. }\end{array}$} & Mix ID A & MIX ID B & MIX ID C & MIX ID D & MIX ID E \\
\hline & \multicolumn{5}{|c|}{$\begin{array}{l}\text { Average values from two or three samples (ø150x300 mm cyl.) } \\
\text { (Real age in days at testing) Compressive strength in } \mathrm{MPa}\end{array}$} \\
\hline $\begin{array}{l}10^{\circ} \mathrm{C} \\
\text { First and sec- } \\
\text { ond* test se- } \\
\text { ries }[11]\end{array}$ & $\begin{array}{c}(2.04) 13.2 \\
(4.06) 25.3 \\
(14.1) 45.0 \\
(56.1) 58.9 \\
(127.0) 71.8\end{array}$ & $\begin{array}{c}(2.04) 9.7 \\
(4.17) 19.4 \\
(14.1) 35.1 \\
(56.1) 49.9 \\
(120.1) 59.0\end{array}$ & $\begin{array}{c}(2.00) 26.7 \\
(4.07) 42.1 \\
(14.2) 56.0 \\
(56.2) 72.1 \\
(113.1) 75.6\end{array}$ & $\begin{array}{c}(2.05) 23.7 \\
(4.10) 36.8 \\
(14.2) 51.5 \\
(56.1) 67.9 \\
(113.2) 72.4\end{array}$ & $\begin{array}{c}(2.07) 6.2 \\
(4.11) 14.2 \\
(14.1) 41.1 \\
(14.1) 35.9 * \\
(56.1) 61.6 \\
(114.1) 70.2\end{array}$ \\
\hline $\begin{array}{l}20^{\circ} \mathrm{C} \\
\text { First and sec- } \\
\text { ond* test se- } \\
\text { ries [11] }\end{array}$ & $\begin{array}{c}(1.00) 12.7 \\
(2.01) 23.2 \\
(6.99) 39.7^{*} \\
(7.02) 41.4 \\
(28.0) 58.5 \\
(56.1) 67.3 \\
(179.0) 77.5\end{array}$ & $\begin{array}{c}(1.01) 9.1 \\
(2.00) 17.8 \\
(7.01) 32.5 \\
(7.12) 35.8^{*} \\
(28.0) 48.4 \\
(56.0) 59.6 \\
(175.1) 74.67\end{array}$ & $\begin{array}{c}(1.02) 28.5 \\
(2.01) 39.0 \\
(7.01) 54.3 \\
(28.1) 64.1 \\
(56.0) 67.4 \\
(178.1) 71.3\end{array}$ & $\begin{array}{c}(1.00) 21.8 \\
(2.00) 36.0 \\
(7.00) 50.7 \\
(7.02) 54.3^{*} \\
(28.0) 68.5 \\
(56.0) 75.6 \\
(182.2) 87.8\end{array}$ & $\begin{array}{c}(0.97) 5.0 \\
(2.01) 17.2 \\
(7.23) 47.1 \\
(28.0) 66.1 \\
(56.1) 70.0 \\
(179.1) 77.1\end{array}$ \\
\hline $\begin{array}{l}30^{\circ} \mathrm{C} \\
\text { First and sec- } \\
\text { ond* test se- } \\
\text { ries }[11]\end{array}$ & $\begin{array}{c}(0.65) 14.3 \\
(1.27) 22.8 \\
(4.41) 39.8 \\
(4.44) 36.7^{*} \\
(17.9) 55.7 \\
(35.9) 64.3 \\
(114.1) 72.3^{*} \\
(233.0) 72.4^{*} \\
\end{array}$ & $\begin{array}{c}(0.61) 10.5 \\
(1.26) 19.6 \\
(4.40) 33.3^{*} \\
(4.41) 34.2 \\
(17.9) 58.7 \\
(35.2) 67.0 \\
(114.2) 71.2^{*} \\
(228.0) 84.8^{*}\end{array}$ & $\begin{array}{c}(0.64) 31.7 \\
(1.26) 41.5 \\
(4.44) 54.4 \\
(4.45) 59.4^{*} \\
(17.9) 62.8 \\
(35.3) 66.6 \\
(114.2) 75.0^{*}\end{array}$ & $\begin{array}{c}(0.63) 25.6 \\
(1.26) 36.6 \\
(4.42) 50.8 \\
(4.45) 52.9^{*} \\
(18.0) 70.7 \\
(35.2) 74.3 \\
(114.2) 88.4^{*} \\
(229.0) 88.8^{*}\end{array}$ & $\begin{array}{c}(0.61) 10.3 \\
(1.31) 26.9 \\
(4.34) 50.1 \\
(4.41) 42.1^{*} \\
(17.9) 64.4 \\
(35.2) 64.6 \\
(114.2) 62.1^{*}\end{array}$ \\
\hline $\begin{array}{l}\quad 45^{\circ} \mathrm{C} \\
\text { First and sec- } \\
\text { ond* test se- } \\
\text { ries }[11]\end{array}$ & $\begin{array}{c}(0.34) 10.9 \\
(0.68) 19.4 \\
(2.35) 33.6 \\
(2.37) 31.7^{*} \\
(9.49) 49.3 \\
(19.3) 56.1 \\
(61.1) 58.8^{*} \\
(121.1) 60.7^{*} \\
\end{array}$ & $\begin{array}{c}(0.34) 8.9 \\
(0.64) 16.0 \\
(2.37) 31.2 \\
(2.37) 30.6^{*} \\
(9.46) 53.9 \\
(19.0) 61.5 \\
(60.3) 64.1^{*} \\
(122.2) 68.2^{*} \\
\end{array}$ & $\begin{array}{c}(0.34) 27.0 \\
(0.67) 35.0 \\
(2.36) 47.2 \\
(2.39) 51.0^{*} \\
(9.51) 52.4 \\
(19.3) 56.8 \\
(60.2) 60.8^{*}\end{array}$ & $\begin{array}{c}(0.34) 22.7 \\
(0.65) 30.5 \\
(2.36) 47.9 \\
(2.37) 48.4^{*} \\
(9.40) 65.4 \\
(19.2) 70.5 \\
(61.1) 74.6^{*} \\
(121.2) 73.8^{*}\end{array}$ & $\begin{array}{c}(0.33) 7.6 \\
(0.64) 21.8 \\
(2.35) 39.6^{*} \\
(2.36) 47.6 \\
(9.41) 55.2 \\
(19.1) 57.6 \\
(60.1) 53.3^{*}\end{array}$ \\
\hline $\begin{array}{l}\quad 60^{\circ} \mathrm{C} \\
\text { First and sec- } \\
\text { ond* test se- } \\
\text { ries }[11]\end{array}$ & $\begin{array}{c}(0.20) 8.7 \\
(0.38) 17.1 \\
(1.32) 29.0 \\
(1.97) 30.5^{*} \\
(5.35) 41.8 \\
(10.9) 48.2 \\
(34.2) 52.6^{*} \\
(69.0) 51.8^{*}\end{array}$ & $\begin{array}{c}(0.20) 7.2 \\
(0.35) 14.2 \\
(1.31) 32.4 \\
(1.33) 32.7^{*} \\
(5.42) 46.6 \\
(10.9) 49.4 \\
(35.0) 48.8^{*}\end{array}$ & $\begin{array}{l}(0.18) 22.0 \\
(0.36) 38.1 \\
(1.28) 41.0 \\
(5.37) 45.3 \\
(10.9) 47.5\end{array}$ & $\begin{array}{c}(0.21) 18.6 \\
(0.36) 25.7 \\
(1.32) 48.9 \\
(1.34) 47.3^{*} \\
(5.32) 56.6 \\
(11.0) 58.3 \\
(34.3) 58.5^{*}\end{array}$ & $\begin{array}{c}(0.20) 3.1 \\
(0.36) 18.2 \\
(1.33) 44.1 \\
(1.34) 36.7^{*} \\
(5.38) 47.0 \\
(10.9) 50.2 \\
(35.0) 54.9^{*}\end{array}$ \\
\hline
\end{tabular}


Nordic Concrete Research - Publ. No. NCR 62 - ISSUE 1 / 2020 - Article 5, pp. 87-106

\begin{tabular}{|c|c|c|c|c|c|}
\hline \multirow[b]{2}{*}{$\begin{array}{l}\text { Nominal } \\
\text { temp. }\end{array}$} & Mix ID A & MIX ID B & MIX ID C & MIX ID D & MIX ID E \\
\hline & \multicolumn{5}{|c|}{$\begin{array}{l}\text { Average values from two or three samples }(\varnothing 100 \times 200 \mathrm{~mm} \text { cyl.) } \\
\text { (Real age in days at testing) Compressive strength in } \mathrm{MPa}\end{array}$} \\
\hline \multirow{5}{*}{$\begin{array}{l}5^{\circ} \mathrm{C} \\
\text { Third test se- } \\
\text { ries [12] }\end{array}$} & (5.17) 27.0 & 27.0 & \multirow{5}{*}{ - } & (3.46) 25.0 & 15.0 \\
\hline & 35.0 (10.3) & 33.0 (13.6) & & 35.0 & 18.0 (8.25) \\
\hline & 46.0 (24.0) & 39.0 (27.0) & & 40.0 (6.96) & 24.0 (11.0) \\
\hline & 60.0 & 50.0 (48.0) & & (10.4) 45.0 & 35.0 (18.0) \\
\hline & 67.0 & 67.0 & & 70.0 & 58.0 \\
\hline \multirow{4}{*}{$\begin{array}{l}10^{\circ} \mathrm{C} \\
\text { Third test se- } \\
\text { ries }[12]\end{array}$} & (3.04) 22.0 & 23.0 & \multirow{4}{*}{ - } & 22.0 & 17.0 \\
\hline & (6.08) 32.0 & 30.0 (8.08) & & 30.0 (3.04) & 19.0 (5.08) \\
\hline & 40.0 (14.2) & 36.0 (14.2) & & 36.0 & 22.0 \\
\hline & 51.0 & 46.0 & & (6.04) 41.0 & 35.0 \\
\hline \multirow{5}{*}{$\begin{array}{l}20^{\circ} \mathrm{C} \\
\text { Third test se- } \\
\text { ries [12] }\end{array}$} & 21.0 & 23.0 & \multirow{5}{*}{ - } & 23.0 (1.00) & 19.0 (2.04) \\
\hline & (3.04) 29.0 & (4.04) 30.0 & & 29.0 (1.46) & 23.0 \\
\hline & 37.0 (7.04) & 36.0 (7.08) & & 37.0 (2.04) & 28.0 (3.08) \\
\hline & 50.0 & (14.0) 45.0 & & (3.04) 40.0 & 38.0 \\
\hline & 59.0 (28.0) & 54.0 (28.0) & & 60.0 & 59.0 (28.0) \\
\hline \multirow{5}{*}{$\begin{array}{l}30^{\circ} \mathrm{C} \\
\text { Third test se- } \\
\text { ries [12] }\end{array}$} & 24.0 & 20.0 (1.33) & \multirow{5}{*}{ - } & (0.67) 24.0 & 22.0 \\
\hline & 30.0 & (2.58) 25.0 & & 32.0 (1.00) & (1.58) 27.0 \\
\hline & (4.50) 37.0 & 31.0 (4.50) & & 35.0 (1.33) & 30.0 (1.96) \\
\hline & (8.92) 48.0 & (8.96 43.0 & & (1.96) 41.0 & 38.0 \\
\hline & (18.0) 28.6 & 54.0 & & 66.0 & 56.0 \\
\hline \multirow{5}{*}{$\begin{array}{l}45^{\circ} \mathrm{C} \\
\text { Third test se- } \\
\text { ries }[12]\end{array}$} & (0.54) 20.0 & 16.0 & \multirow{5}{*}{ - } & (0.38) 20.0 & 19.0 (0.63) \\
\hline & 27.0 (1.08) & 26.0 (1.42) & & 29.0 (0.63) & 29.0 (0.92) \\
\hline & 37.0 & (2.33 31.0 & & (0.67) 30.0 & 30.0 (1.04) \\
\hline & (5.00) 46.0 & (5.04) 47.0 & & 36.0 (1.04) & (1.58) 36.0 \\
\hline & 51.0 & 58.0 & & 63.0 & (9.33) 48.0 \\
\hline \multirow{5}{*}{$\begin{array}{l}\quad 60^{\circ} \mathrm{C} \\
\text { Third test se- } \\
\text { ries [12] }\end{array}$} & 17.0 & 16.0 & \multirow{5}{*}{-} & 14.0 & 18.0 \\
\hline & (0.63) 25.0 & 23.0 & & (0.33) 23.0 & (0.46) 25.0 \\
\hline & 33.0 (1.38) & 35.0 (1.38) & & (0.42) 26.0 & 33.0 \\
\hline & 39.0 (2.54) & 44.0 (2.58) & & 32.0 & 39.0 (1.00) \\
\hline & 45.0 & (5.38) 49.0 & & 55.0 & 46.0 \\
\hline
\end{tabular}

